\section{SUPLEMENTAÇĀO DE COLINA PARA POEDEIRAS COMERCIAIS HISEX BROWN E HISEX WHITE. 1. DESEMPENHO DAS} AVES E QUALIDADE DO OVO*

\section{CASSID XAUIER DE MENDONGA JUNIOR Professor Adjunto Faculdade de Medicina Veterinaria e Zootecria da USP}

MENDONCA JUNIOR, [.X. Suplementagå de colina para poedeiras comerciais $\mathrm{Hi}$ sex Brown e Hisex white. 1. Desempenho das aves e qualidade do ovo. Rev. Fac. Med. Vet. Zootec. Univ. 5. Paulo, $25(2): 297-307,1988$.

RESUMO: [ento e vinte e oito galinhas, 64 da Linhagem Hisex Brown e 64 da li nhagem Hisex White, apresentando respectivamente, 63 e 64 semanas de idade, foram alimentadas com raçâs à base de milho e farelo de soja contendo suplementaço de 500, 1000, 1500 e $2000 \mathrm{mg} d e$ colina por quilo e nivel constante de $0,253 \%$ de metionina para todas as dietas experimentais, correspondendo a $80 \%$ das necessidades estabelecidas pelo National Research Council. D experimento teve a duraço de 4 ciclos de 28 dias, sendo constituldo de 16 galinhas por tratamento. Nao foram consignadas diferencas entre as linnagens estudadas no relativo à producaro de ovos, conversaro alimentar lexpressa em kg de racăo por kg de ovol e porcentagem de casca dos ovos. A eficiência alimentar (consumo de raça por duzia de ova) e a qualidade da albumen (unidades Haugh) foram significativamente melhores para a linhagem Hisex White. Os ovos vermelhos apresentaram valores de espessura da casca e de gravidade especifica significativamente maiores que os auferidos para os ovos brancos. A inclusao de colina a raça na revelou efeito significativo sobre desempenho das aves e qualidade do abbumen (unidades Haugh) mostrando-se, no entanto, efetiva no aumento da qualidade da casca (porcentagem da casca, espessura da casca e gravidade especifica dos ovos).

UNITERMOS: Colina; Ovos, qualidade da casca; Gabininas poedeiras, desemontio
INTRODUCAO

Várias pesquisas (CRAWFORD et alii 4. 1969; NESHEIN et alii, 22, 1971; MARCH, 16, 1981; RUIZ et alii, 23, 1983) têm revelado que as galinhas teriam capacidade de sintetizar consideraveis quantidades de colina, requerendo portanto minima, ou mesmo nenhuma, suplementaço dietética desta vitamina, quando a metionina estivesse em niveis adequados na racaro. Em contrapartida, a colina teria eteito benefico no aumento do peso dos ovos e no indice de postura, quando adicionada a raças deficientes em metionina e vitamina 812 (GRIFFITH et ali i , 10, 1969; SCHEXNAILDER \& GRIFFITH, 24, 1973). MILES \& HARMS, 17 (1984), MILES et alii, 19 (1984), KESHAUARZ \& AUSTIC, 15 (1985) e MILES et alii. 20 (1986) sugeriram, por sua vez, que este efeito da colina seria sentido apenas na producalo de ovos, sendo necessario que nlveis adequados de aminoacidos sulfurados estivessem presentes para possibilitar peso maximo dos ovos. Ja HENNIG et alii, 12 (1985) nåo constataram qualquer beneflcio da adicao de colina às raçoses, sobre o peso e produço de ovos.

TSIAGBE et alii, $26(1982)$ conclulram que as necessidades de colina para galinhas poedeiras estariam entre 1000 e 1500 ppm, em raçäes sem suplementacaro de metionina. Por outro lado, CRAWFORD et alii, 3,4 (1967, 1969), BROOKS \& CREGER, 1 (1983) e MILES et alii, 20 (1986) sugeriram niveis mais baixos, entre 595 e $700 \mathrm{mg}$ de colina por quilo de dieta, como exigencias minimas para poedeiras, contrariando as afirmativas de RuIZ et alii, 23 (1983) que, utilizando galinhas Hisex, nao consignaram qualquer benef 1 cio da suplementaça de colina, entre 55 e $880 \mathrm{mg} / \mathrm{kg}$ de raça a base de milho e $50 j a$, na producăo e peso dos ovos, e conversa alimentar. No Brasil, FERNANDES et alii, 9 (1983) verificaram que a suplementacăo de metionina, para atender as exigências de poedeiras, poderia ser completamente substituida por $0,10 \%$ de colina. MILES \& HARMS, 18 (1985) recomendam que uma galinha deve consumir cerca de 118 mg de colina, diariamente, para garantir a năo necessidade de utilizacăo dos aminoacidos sulfurados da raça para atender às funcơes desta vitamina no organismo animal. Esta ingestăo poderia ser alcancada fornecendo-se nlveis dieteticos de colina varianoo entre 1038 e $1526 \mathrm{mg} / \mathrm{kg}$, na dependencia do consumo medio das aves.

No relativo à qualidade dos ovos, HAMILTON, 11 (1982) ressaltou que, como. advento da mecanizacăo no processamento dos ovos, aumentou a incidencia de cascas quebradas desde a produca ate o 
consumo. Assim, atualmente estas valores situam-se entre 7 e $8 \%$, bem superiores às cifras de 1,5 a $2 \%$, obtidas na epoca em que os ovos eram processados manualmente. Neste sentido, o controle deste parametro em exploraça comercial de galinhas para producăo de ovos assume importancia primacial.

Pesquisas têm revelado a existência de diferencas geneticas que afetam a qualidade dos ovos, entre especies, racas, linhagens e familias de galinhas, podendo esta caracteristica ser melhora-

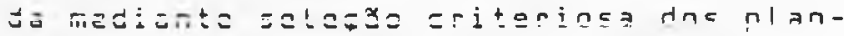
teis (FARMSWORTH JUNIOR \& NORDSKOG, 8 , 1955; BUS5, 2, 1982).

CURTIS et alii, 5,6 (1985) camparando a qualidade de ovos vermelhos e de ovos brancos, concluiram que a espessura e a porcentagem da casca revelaram-se significativamente maiores nos ovos brancos, enquanto que os valores de unidades Haugh foram mais elevados nos vermelhos.

Quanto aos efeitos da idade da ave e das estacoses do ano sobre a qualidade dos ovas, IZAT et alii, 13,14 (1985, 1986) consignaram que a espessura da casca foi menor no vera e a gravidade especifica maior nas aves jovens durante as estaç㐅es mais frias. 0 peso e porcentagem da casca tambem sofreram influência da idade e da estaço do ano. A porcentagem de casca e os valores de unidades Haugh diminuiram com o avancar da idade. BUSS, 2 (1982) ressaltou, por outro lado, que a qualidade da casca seria indeoendente do indice de postura e do peso dos ovos.

TSIAGBE et alii, 26 (1982) e RUIZ et alii, 23 (1983) demonstraram que a suplementaca de colina às dietas nao afetou, respectivamente, a espessura da casca e a gravidade especifica dos ovos, medidas estas que refletem a resistência da casca.

0 presente experimento tem por finalidade estudar o desempenho e a qualidade dos ovos de poedeiras Hisex White (leve) e Hisex Brown (semi-pesada) submetidas a dietas contendo niveis subotimos de metionina e quantidades crescentes de colina suplementar.

\section{MATERIAL E METODOS}

0 presente experimento foi conduzido nas dependencias da Disciplina de Doencas Nutricionais a Muiaoolicas do Departamento de Clinica Medica da Faculdade de Medicina Veterinaria e Zootecnia da Universidade de Sao Paulo, "Lamous da Cidade Universitaria".

Durante a fase experimental foram registradas as temoeraturas, maxima e minima, vigentes no interior das instalaçes das aves, utilizando-se termóme- tro de maxima e minima.

Foram utilizadas 128 galinhas, sendo 64 da linhagem Hisex Brown e 64 da linhagem Hisex White que contavam, Dor ocasiă do inlcio do experimento. respectivamente com 63 e 64 semanas de idade.

Utilizou-se, para o presente experimento, esquema fatorial $2 \times 4$, com os fatores: Linhagens de aves (Hisex Brown e Hisex White) e nlveis de colina suplementar (500, 1000, 1500 e $2000 \mathrm{mg} / \mathrm{kg}$ ). As galinhas foram alojadas, 2 por gaiola, de modo a serem formados, para cada linhagem, 8 lotes de 8 aves, constitulindo-se, portanto, no total, 8 tratamentos com 16 aves por tratamento. Cada Lote era constituido por um conjunto de 4 gaiolas, cada uma medindo $0,45 \mathrm{~m} x$ $0,25 \mathrm{~m} \times 0,45 \mathrm{~m}$, e de um comedouro, sendo a água fornecida em bebedouro tipo caltha.

As aves foram distribuidas de modo a apresentarem pesos, corporal e dos ovos, bem proximos nos diferentes tratamentos estudados, recebendo, durante todo o periodo experimental, um total de 16 horas diarias de luz.

As raços experimentais, fornecidas ad libitum, foram isocaldricas e isoproteicas (Tab. 1), adotanda-se, para todas as dietas estudadas, o nivel de $0,253 \%$ de metionina, correspondendo a 80\% das necessidades estabelecidas pelo NATIONAL RESERRCH COUNCIL, 21 (1984).

0 experimento foi conduzido em 4 ciclos de 28 dias, tendo sido iniciado em $10 / 04 / 86$ e terminado em 31/07/86.

Ds ovas foram colnidos diariamente, a fim de se obter o peso medio dos mesmos e o registro da producăo.

Nos três ultimos dias de cada ciclo, os ovos faram colhidos das 8 as 12 horas, pesados, procedendo-se, em seguida, à determinacăo da gravidade especlfica dos mesmos, utilizando-se o metodo das solucốes salinas, idealizado por HAMILTON, 11 (1982). Os ovos foram entao quebrados para avaliaça da qualidade do albumen, em unidades Haugh, utilizandose micrômetro Ames, 58400 .

As cascas foram lavadas, mantidas en estufa a 60 o $[$ por 24 horas para secagem, em seguida pesadas em balanca analitica e procedendo-se à medida da espessura das mesmas mediante micrómetro Fines 25M-5.

As aves e as sobras de racăo foram pesadas ao término de cada ciclo de 28 dias para abtenca do peso corporal, consumo alimentar, conversago de racao por duzia e por quilo de ovos produzidos.

Os resultados obtidos foram suometidos à analise de variancia seguno preceitua SNEDECOR \& COCHRAN, 25 (1967) sendo a comparacao entre medias realiza da delo teste de Duncan (DUNCAN, 7 . 1955). 
RESULTADOS

Durante a realizacao do presente experimento os dados medios de temperatura variaram de um valor minimo de $20.0^{\circ} \mathrm{C}$ a um maximo de $28,8{ }^{\circ} \mathrm{C}$ (Tab. 2).

TABELA 1 - Composicao percentual das dietas

Dietas
Ingredientes
Fuba

TABEla 2 - Valores medios de temperaturas minima e maxima, expressos em $[$, obtidos durante os 4 ciclos experimentais. Sao Paulo, 1986 .

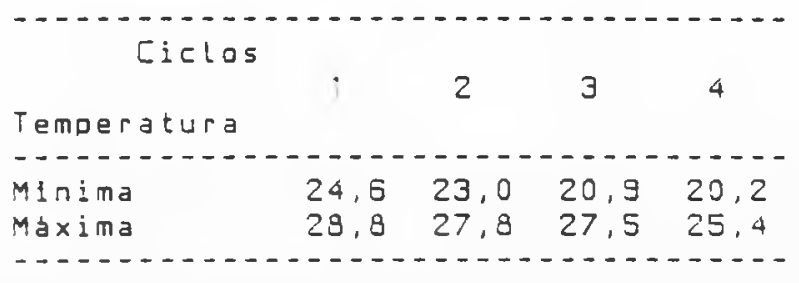


A) Desemoenno das aves

Na Tab. 3 să mostrados os resulta- dos atinentes ao peso vivo (inicial finall das aves, bem como a produca e o peso medio dos ovas obtidos nos 4 ciclos de postura.

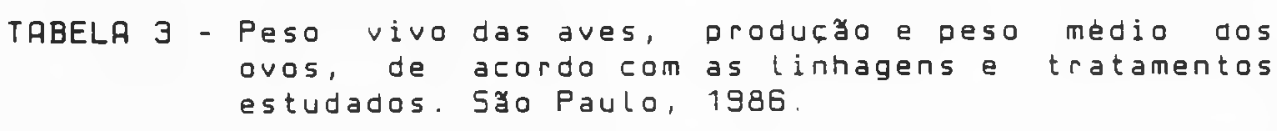

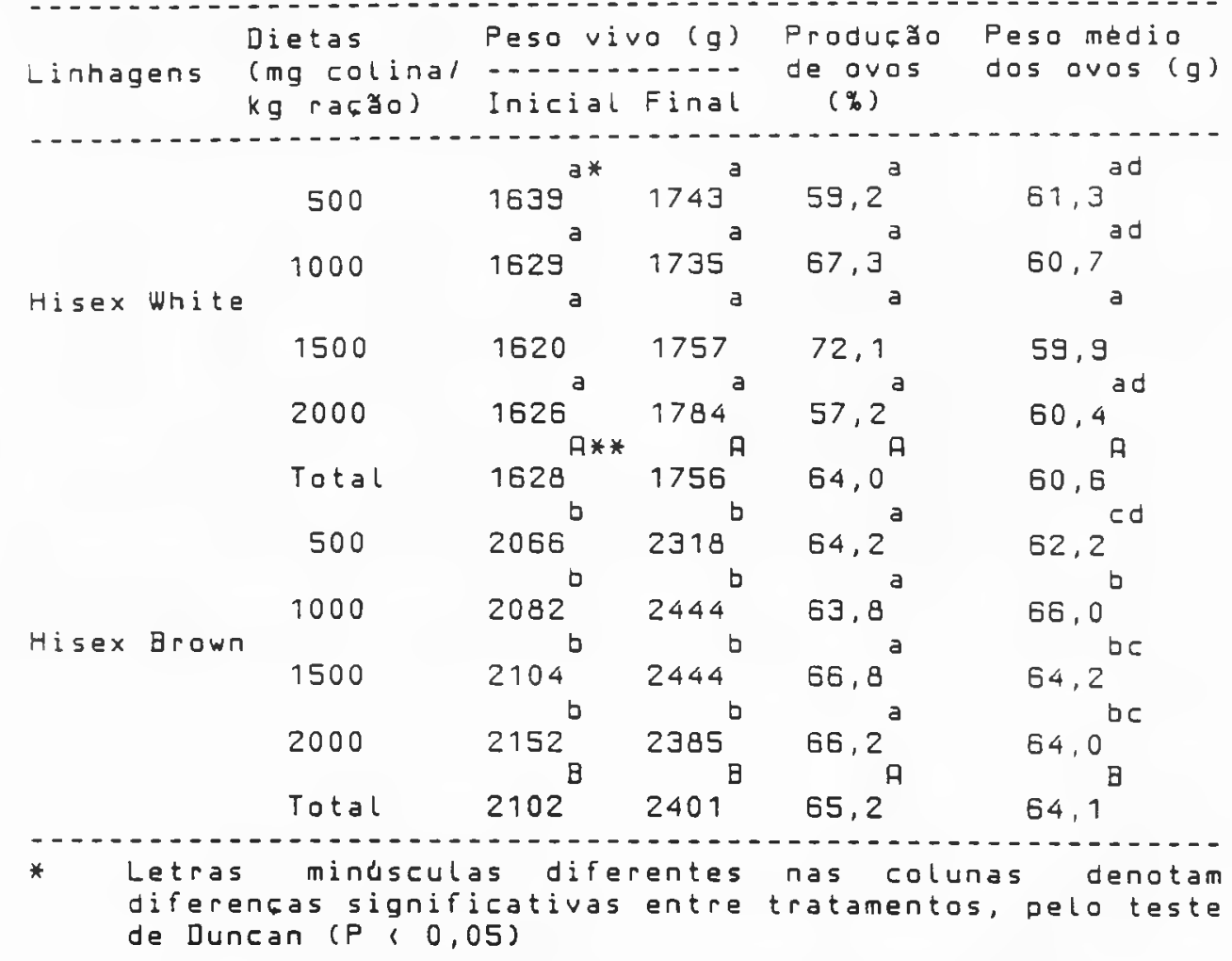

* Letras maiusculas diferentes nas colunas revelam diferencas significativas entre linhagens, pela analise de variância $(P, 0,05)$

Nao foram assinaladas diferencas
de significado estatistico na producao
media de ovos odtida oor eiclo, entre as
linnagens Hisex White e Hisex Brown. Por
outro bado, esta d blima linhagem (semi-
pesada) evidenciou, como era esperado,
peso corporal edos ovos, significativa-

Rev. Fac. Med. Vet. Zootec. Univ. S. Paulo, 25(2): 297-307, 1988. mente mais elevados que os assinalados Dara a Hisex White, Je porte leve (Tab. 3).

No relativo às dietas, nao foi evidendiado efeito significante soore o peso vivo, produca e peso dos ovos (Tab. 4). 
MENDONÇA JUNIOR, C.X.

Suplementação de colina para poedeiras comerciais Hisex Brown e Hisex White

$\begin{aligned} \text { TABELA } 4 \text { - } & \text { Peso vivo, numero e peso dos ovos } \\ & \text { das galinhas submetidas as dife- } \\ & \text { rentes dietas experimentais ( } 1 \text { i- } \\ & \text { nhagens combinadas). Sao paulo, } \\ & 1986 .\end{aligned}$

\begin{tabular}{|c|c|c|c|c|}
\hline $\begin{array}{l}\text { Colina } \\
(\mathrm{mg} / \mathrm{kg})\end{array}$ & \begin{tabular}{l} 
Peso vi \\
\hdashline---- \\
Inicial
\end{tabular} & $\begin{array}{l}\text { vo }(g) \\
---- \\
\text { Final }\end{array}$ & $\begin{array}{l}\text { Producă } \\
\text { de ovos } \\
(\%)\end{array}$ & $\begin{array}{c}\text { Peso medio } \\
\text { dos ovos } \\
(\mathrm{g})\end{array}$ \\
\hline & $\begin{array}{c}a * \\
a *\end{array}$ & $\begin{array}{r}\cdots \\
a\end{array}$ & $\begin{array}{r}a \\
a\end{array}$ & $\begin{array}{c}------ \\
a\end{array}$ \\
\hline 500 & 1838 & 2031 & $\begin{array}{r}61,7 \\
\text { a }\end{array}$ & $\begin{array}{r}81,7 \\
\text { a }\end{array}$ \\
\hline 1000 & $1863^{3}$ & 2102 & 65,6 & 63,4 \\
\hline 1500 & $1870^{\circ}$ & $2112^{a}$ & $69,4^{a}$ & 62,0 \\
\hline $\begin{array}{l}\text { * Letras } \\
\text { revelam }\end{array}$ & $\begin{array}{r}\text { mindsc } \\
\text { dife }\end{array}$ & ulas d & $\begin{array}{l}\text { fignific } \\
\text { figntes }\end{array}$ & $\begin{array}{l}\text { nas colunas } \\
\text { tivas entre }\end{array}$ \\
\hline
\end{tabular}

As aves da linhagem Hisex Brown evidenciaram consumo de racăo significativamente mais elevado que a Hisex White. A converså alimentar, quando expressa em quilo de racaro por duzia de ovos, mostrouse significativamente mais eficiente para a Linhagem Hisex White. No entanto, quando este Indice foi calculado considerando-se a produça em quilo de ovos, nåo se evidenciaram diferencas significativas entre as linhagens estudadas (Tab. 5 ).

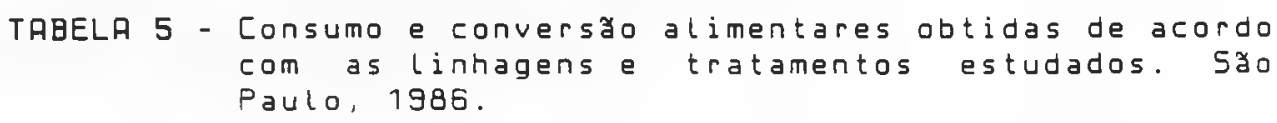

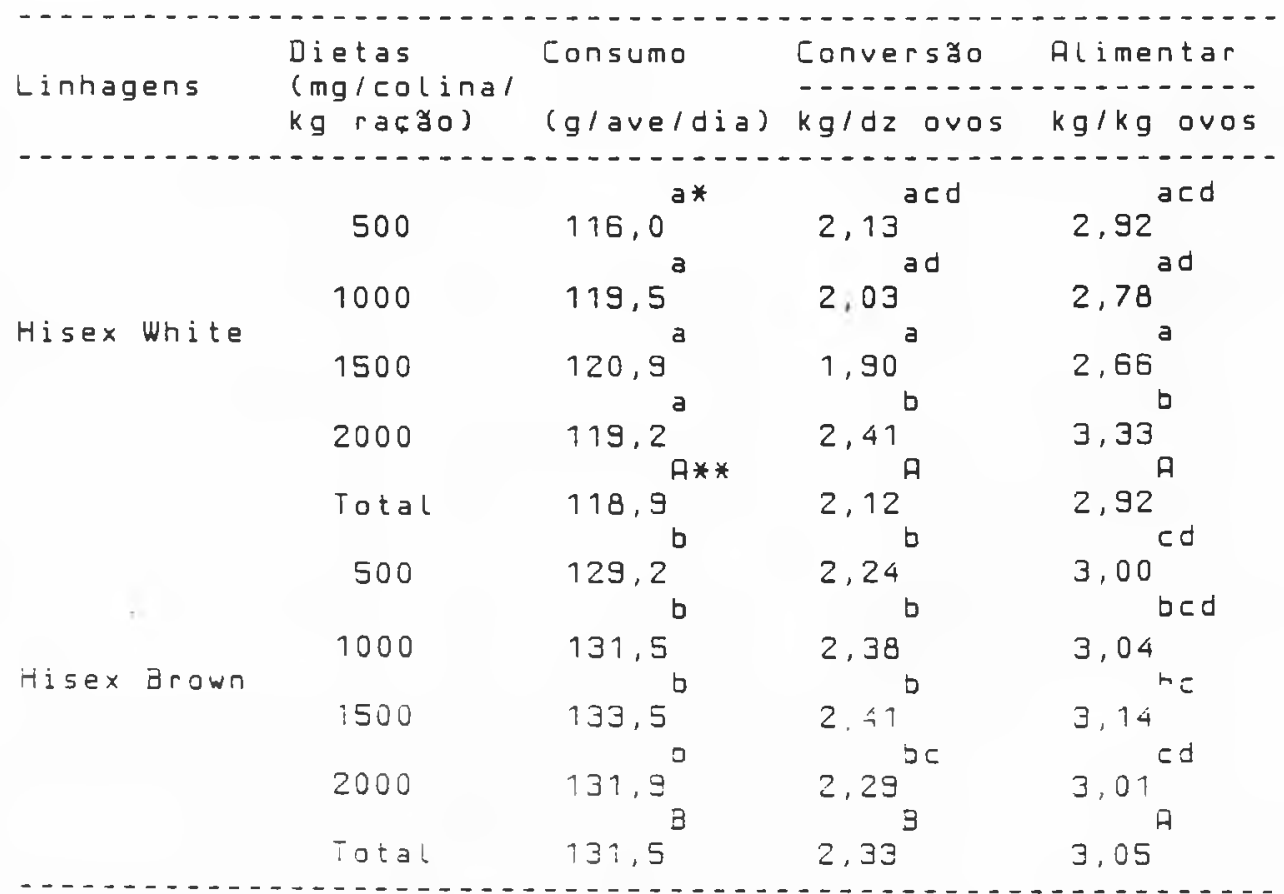

* Letras minusculas diferentes nas colunas revelam diferenças significativas entre iratamentos, pelo teste de Duncan $(\mathrm{P}<0.05$ )

** Letras maiúsculas diferentes nas colunas expressam diferenças significativas entre linhagens, pela aná. lise de variància $(\mathrm{P}<0,05)$ 
302 MENDONÇA JÚNIOR. C.X.

Suplementaçdo de colina para poedeuras comercias Hisex Brown e Hisex White

Se for agora considerada a influência dos diferentes niveis de colina sud lementar, sobre os indices de conversăo alimentar, pode-se observar que as racaes contendo $2000 \mathrm{mg}$ de colina por quilo, proporcionaram os piores valores de conversao, quando comparados com aqueles auferidos para as dietas contendo 500, 1000 e $1500 \mathrm{mg}$ desta vitamina. No entanto, apenas para a conversao alimentar, expressa em consumo de raça por quilo de ovos produzidos, a diferenca mostrou-se de significado estatistico ( Tab. 6). g) Qualidade dos ovos

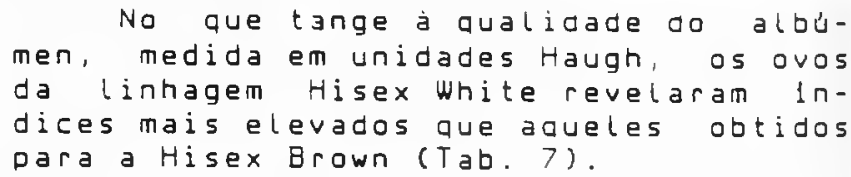

TRBElA 7 - Qualidade do albúmen (unidades Haugh) dos ovos obtidos de ambas as linhagens submetidas às diferentes raços experimentais. Sao Paulo, 1986 .

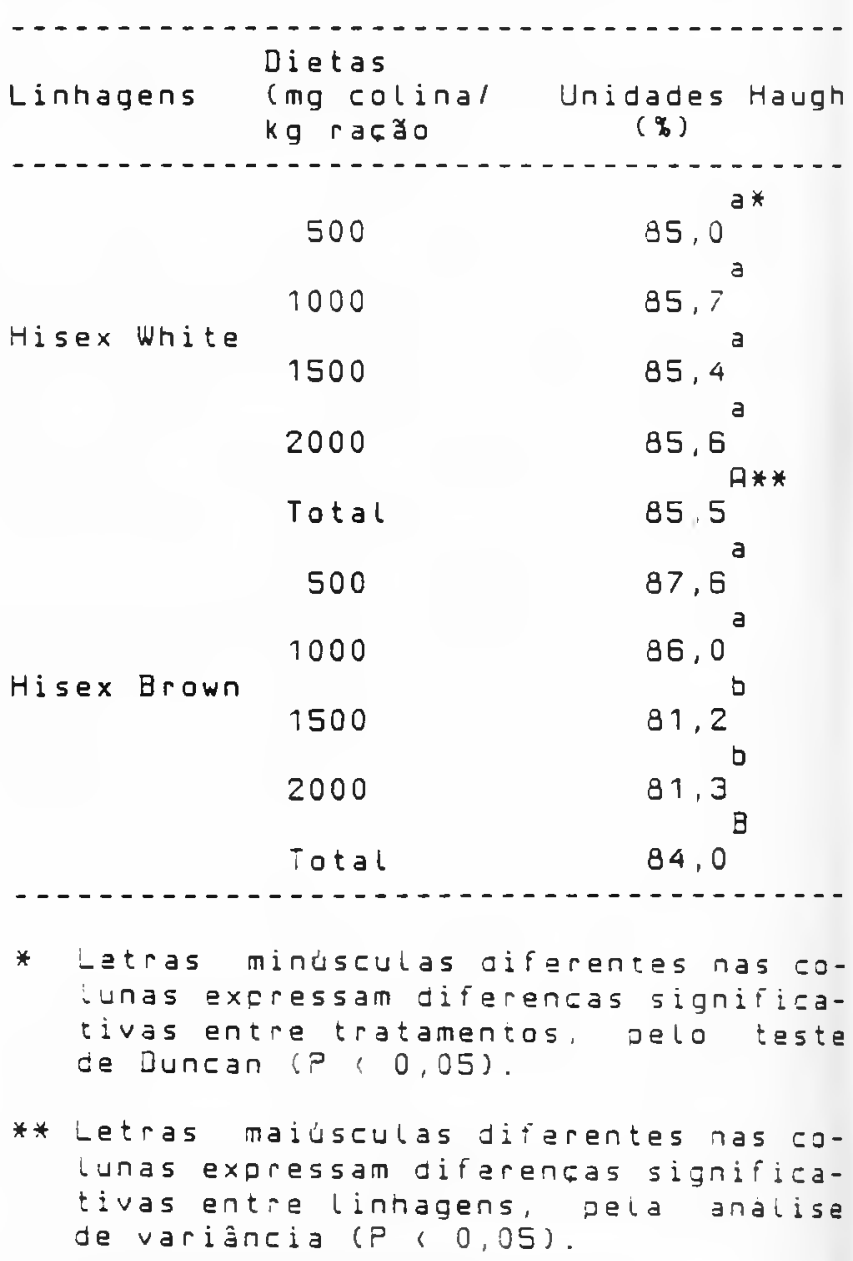

Rev. Fac. Med. Vet. Zootec. Univ. S. Paulo. 25(2):297-307, 1988.

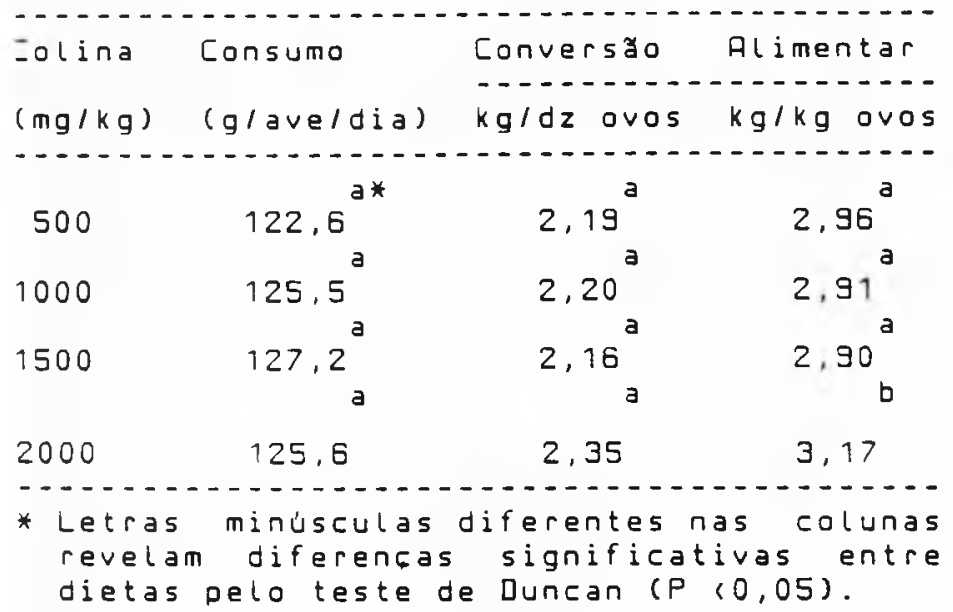


As dietas contendo 1500 e $2000 \mathrm{mg}$ ae colina por quilo, apresentaram valores de unidades Haugh significativa- mente inferiores aos obtidos para as racores com 500 e $1000 \mathrm{mg}$ desta vitamina ( Tab. B).

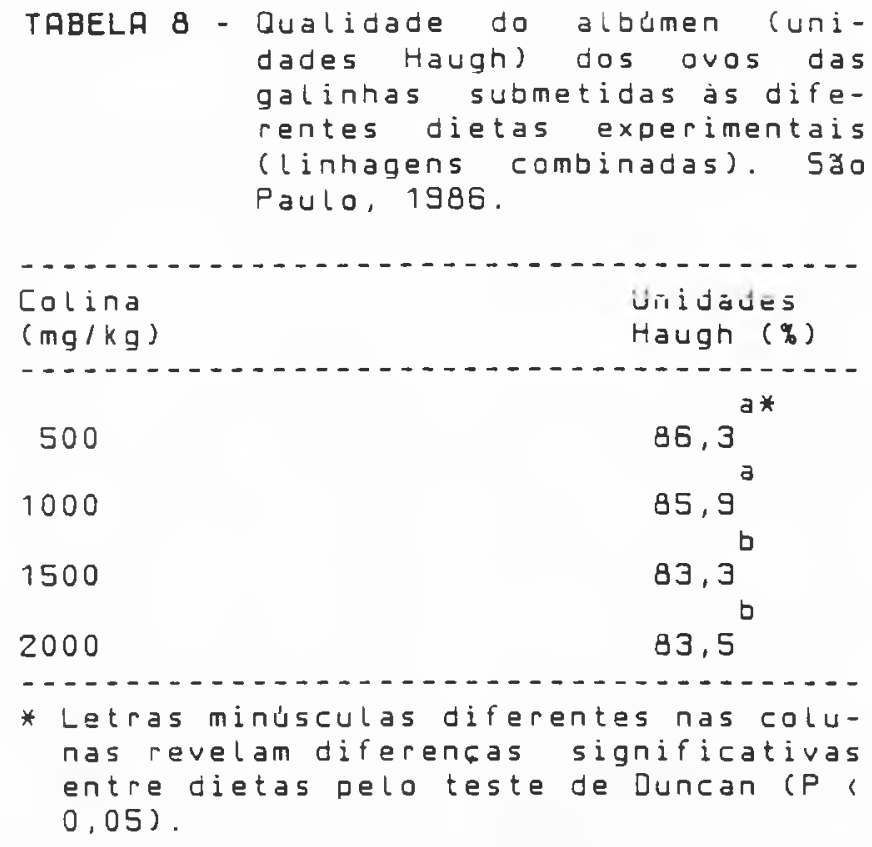

Quanto à qualidade da casca, auferida pelo peso da casca, expresso como percentual do peso do ovo, espessura da casca e gravidade espectfica do ovo, foram evidenciados melhores resultados para a Linhagem Hisex Brown. Com exceca o da porcentagem da casca, as demais medidas revelaram diferencas significativas nos contrastes efetuados entre linhagens (Tab. 9).

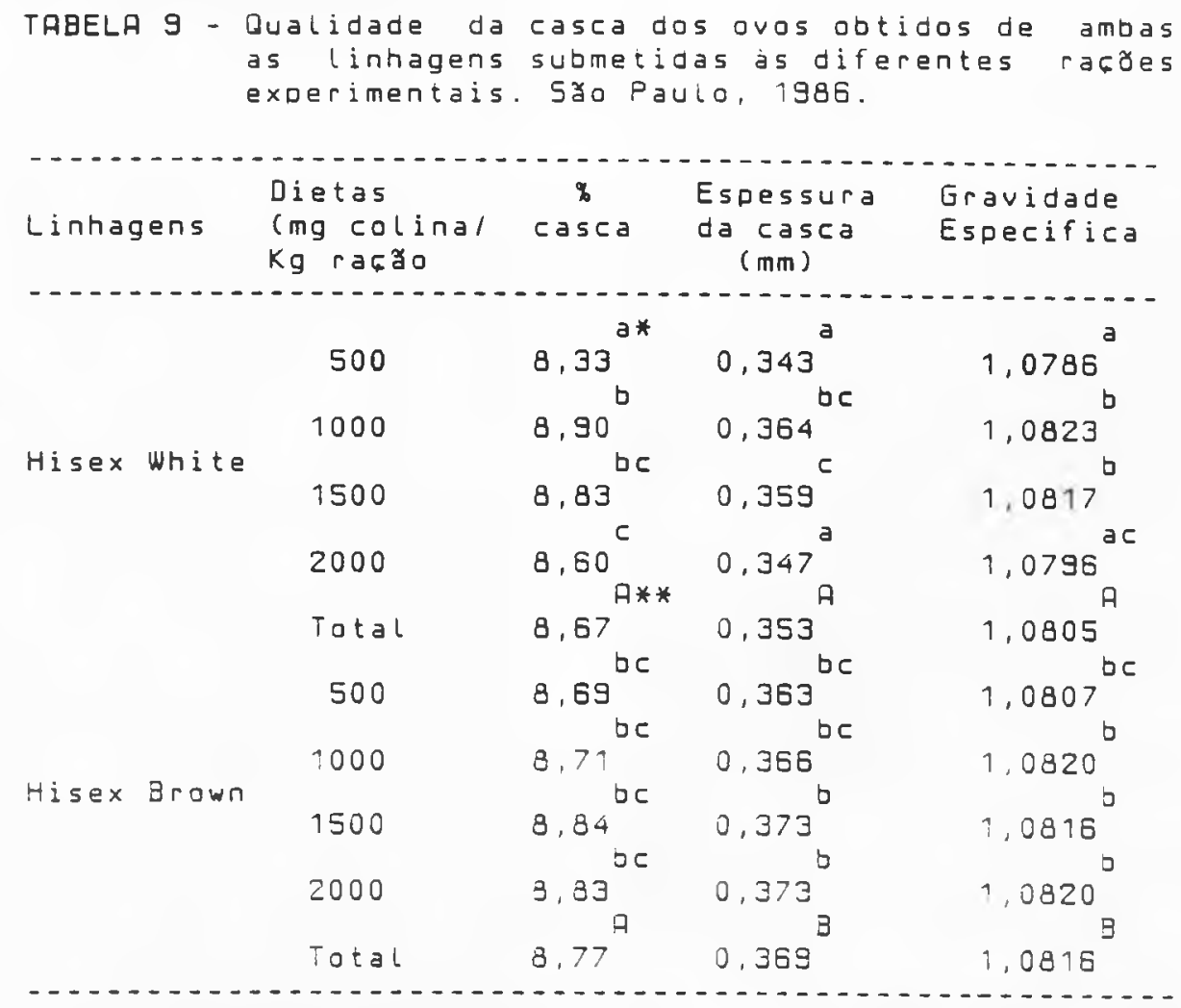

* Letras minuisculas diferentes nas colunas expressam diferenças significatvas entre tratamentos, peio teste de Duncan $(\mathrm{P}<0.05)$.

* * Letras maiúsculas diferentes nas colunas expressam diferenças signuricativas entre linhagens. pela anali. se de vanància $(\mathrm{P}<0,05)$. 
A suplementacaro de colina em niveis de 1000, 1500 e $2000 \mathrm{mg}$ por quilo de dieta, proporcionou melhora da qualidade da casca dos ovos, revelando diferencas significativas quanda seus valores foran comparados com os auferidos para as aves a limentadas com racaro contendo $500 \mathrm{mg}$ de colina/kg (Tab. 10). $\begin{aligned} \text { TABELA } 10 \text { - } & \text { dualidade da casca dos ovos das } \\ & \text { galinhas submetidas as diferen- } \\ & \text { tes dietas experimentais (li- } \\ & \text { nhagens combinadas). Sao Paulo, } \\ & 1986 .\end{aligned}$

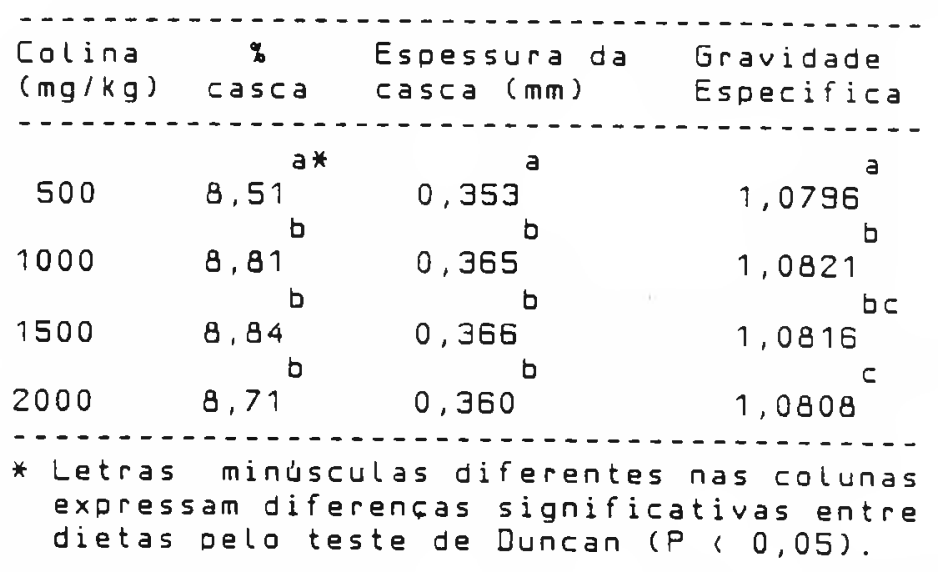

\section{DISCUSSAO}

Desempenho das aves

Ds Indices de producaro de ovos obtidos para as linhagens Hisex White (Leve) e Hisex Brown (semi-pesada) nao revelaram diferencas significativas entre si, corroborando, assim, os resultados de RUIZ et alii, 23 (1983) que nao consignaram influencia do peso corporal sobre este parametro, em galinhas Hisex. Os valares medios de postura, aqui observados (64,0\% para a Hisex White com peso medio de $1628 \mathrm{~g}$ e 65,2\% para Hisex Brown pesando $2102 \mathrm{~g})$, se aproximam dos assinalados por RUIZ et alii, 23 (1983), da ordem de $64,3 \%$ para aves pertencentes ao grupo de peso corporal entre 1801 e 2100 g (extra-pesadas), sendo no entanto, inferiores a cifra Je $67, j b$, obtida para as galinhis de peso medio oscilando entre 1501 e $1600 \mathrm{~g}$ (leves).

Os resultados de postura concordam, ainda, com as assertivas de CRAWFORD et alii, 3, i (1967, 1969) e NESHEIM et alii, 22 (1971) da nå existência de efeito significativo da inclusăo da colina nas dietas de poedeiras.
Quanto ao peso dos ovos, os dados do presente trabalho confirmam auceles obtidos por RUIZ et alii, 23 (1983) que verificaram valores significativamente mais elevados para as aves classificadas como extra-pesadas.

$A$ adicaro de colina à dieta năo resultou em diferencas significativas na producaro e no peso dos ovos, concordando assim, com as observacões de MARCH, 16 (1981); MILES et alii, 19 (1984); HENNIG et alii, 12 (1985), contrariando, contudo, os achados de SCHEXNAILDER \& GRIFFITH, 24 (1973) e TSIAGBE et alii, 26 (1982). Por sua vez, GRIFFITH et alii, 10 (1969); BROOKS \& CREGER, 1 (1983); MILES \& HARMS, 17 (1984); KESHAVARZ \& AUSTIC, 15 (1985); MILES et alii, 20 (1985) assinalaram aumento da produca a peso dos avos mediante inclusao de colina a dietas deficientes em metionina, fato este năo observado no presente trabalho onde tambem foram utilizados niveis sub-btimos deste aminoacido sulfurado.

No relativo ao consumo e canversao alimentares, as diferencas assinaladas entre linhagens ja eram esoeradas. Tais resultados concoraam com as ootidos oor RUIZ et alii, 23 (1983) ao comoararem Indices de conversao alimentar entre gruoos de galinitas Hisex de diferentes Desos coroorais.

Rev. Fac. Med. Vet. Zootec. Univ. S. Paulo, 25(2):297-307, 1988. 
Quanto à influéneia da inclusăo de colina nas dietas sobre a conversao alimentar, nossos dados confirmam as evidencias de NESHEIM et alii, 22 (1971); MARCH, 16 (1981); RUIZ et alii, 23 (1983); MILES et alii, 19 (1984) que na observaram efeito desta vitamina na eficiência da raçăo.

Qualidade dos ovos

Os ovos de casca branca, originarios das aves da Linhagem Hisex White, apresentaram unidades Haugh significativamente maiores que os vermelhos. provenientes da Hisex Brown, discordando dos resultados de CURTIS et alii, 6 (1985) que consignaram, em aves de linhagens Babcock, valores mais elevados deste parametro neste ultimo tipo de ovos. Segundo FARNSWORTH JUNIOR \& NORDSKOG, . 8 (1955), as diferencas na altura do albumen são grandemente influenciadas por fatores geneticos, que poderiam ser responsaveis pelas variaçes aqui observadas. Os valores medios assinalados na presente pesquisa, Dara ambas as linhagens estudadas, estao bem proximos aos consignados por [URTIS et alii, 6 (1985), de 85,1\% para ovos vermelhos e 81,9\% para os brancos, sendo, contudo, inferiores ao valor médio de $91,2 \%$ obtido por FERNANDES et alii, 9 (1983) em ovos brancos. IZAT et alii, 14 (1986) constataram que a idade pode ser responsavel pelas variaças encontradas nos valores de unidades Haugh dos ovos. Os autores obtiveram, para galinhas entre 13 e 15 meses, portanto com idade pro$x$ ima a das aves do presente estudo, media de $74,37 \%$, inferior às aqui auferidas.

A adiça de 1500 e $2000 \mathrm{mg}$ de colina por quilo de racăo determinou diminuiço da qualidade interna do ovo, traduzida por reducão dos valores de unidades Haugh. Os resultados contrariam os obtidos por TSIAGBE et alii, 26 (1982) e FERNANDES et alii, 9 (1983) que nao constataram efeito significativo da adicăo de colina sobre tais unidades.

Quanto a qualidade da casca, expressa em termos de porcentagem e espessura da casca e da gravidade especlfica do ovo, valores mais elevados foram observados para a linhagem Hisex Grown, corroborando, assim, as observa-

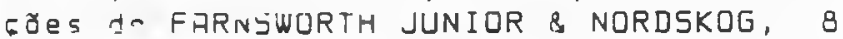
(1955) e 1455,2 (1982) da existéncia de fatores geneticos governando esta caracteristica dos ovos.

EURTIS et abii, 5 (1985) obtiveram valares de porcentagem da casca de $9,35 \%$ e $3,65 \%$, respectivamente para ovos de casca branca e de casca vermelha, sendo o primeiro percentual, bem superior ao consignado para a linhagem Hisex
White $(8,67 \%)$, no presente estudo. Por outro lado, a media obtida para os ovos das galinhas Hisex Brown $(8,77 \%)$ revelou-se superior a auferida pelos autores (CURTIS et alii, 5, 1985) para os ovos de casca vermelha. Nossos dados, mesmo considerando sua diminuicăo com o avancar da idade das aves, situam-se abaixo daqueles assinalados por IZAT et ali i, 13 (1985), em galinhas de mesma faixa etaria que as do presente estudo. Por outro lado, a gravidade especifica aqui obtida mostrou-se mais elevada que as cifras ritadac nalna autnros

RUIZ et alii, 23 (1983) observaram que as aves pesando entre 1200 e 1500 g produziram ovos apresentando valores de gravidade especifica significativamente superiores aos obtidos para galinhas com peso corporal variando entre 1601 e $2100 \mathrm{~g}$, o que contraria os indices encontrados.

IZAT et alii, 13 (1985) constataram valores de espessura da casca entre $0,349 \mathrm{~mm}$ no verão, com temperatura má$\times$ ima de 32,2 o c, e $0,377 \mathrm{~mm}$ no inverno, ocasia em que a temperatura no interior do galpåo poderia cair para $15,6{ }^{\circ}[$. Nossos resultados, obtidos em pertodo abrangendo meses de outono e inverno, cuja temperatura oscilou entre $20,2^{\circ} \mathrm{C}$ e 28,8 o[, portanto intermediaria às citadas por IZRT et alii, 13 (1985), situaram-se tambem na media, ou seja, de $0,369 \mathrm{~mm}$ para a Hisex Brown e de 0,353 $\mathrm{mm}$ para a Hisex White. Este ultimo valor mostrou-se abaixo daqueles assinalados por TSIAGBE et alii, 26 (1982); FERNANDES et alii, 8 (1983); CURTIS et alii, 5 (1985). CURTI5 et alii, 5,6 (1935) assinalaram em ovos brancos, espessura media da casca de $0,390 \mathrm{~mm}$, 5 ignificativamente superior a auferida para os ovos vermelhos $(0,368 \mathrm{~mm})$. Embora este ultimo valor se aproxime do verificado para a linhagem Hisex Brown, os ovos vermelhos revelaram melhor qualidade da casca que os brancos, na presente pesquisa.

A adicăo de colina à raça em niveis de 1000,1500 e $2000 \mathrm{mg} / \mathrm{kg}$, proporcionou aumento na qualidade da casca em relacaro ao teor de $500 \mathrm{mg} / \mathrm{kg}$. RUIZ et alii, 23 (1983), utilizando niveis de colina variando de 0 a $880 \mathrm{mg} / \mathrm{kg}$ de dieta, năo assinalaram influencia desta vitamina na qualidade da casca.

Os resultadas desta pesquisa permitem concluir que a linhagem Hisex Brown (semi-oesada) apresentou desempenho bem proximo ao verificado para a Hisex White (leve), sendo seu elevado cansumo de racăo compensado pelo maior peso dos ovos, oroporcianando desta forma diferenca nă significativa nos lndices de conversalo alimentar, quanoo expressas em consumo de raço por quilo de ovos proauzidos.

Exceça ílita à qualidade do albunen (unidades Haugh) que se revelou melnor para a Linhagem Hisex white,

Rev. Fac. Med. Vet. Zootec. Univ. S. Pauio. 25(2): 297-307, 1988. 
todos os demais parametros utilizados na avaliaço da qualidade da casca mostraram-se mais elevados para a linhagem Hisex Brown.

A adicão de colina à racăo, em nlveis de 500 a $2000 \mathrm{mg} / \mathrm{kg}$, na proporcionou beneflcios na producarc e peso dos ovos, consumo e eficiência alimentares.

NIveis elevados de colina, da ordem de 1000 e $2000 \mathrm{mg}$ por quilo de racra determinaram reducăo na qualidade do albumen (unidades Haugh) e aumento na qualidade da casca (porcentagem da cas$r$ a esposcura ha rasca e gravidade esobcifica dos ovos).

MENDONEA JUNIOR, $ᄃ . X$. Choline supplementation for Hisex White and Hisex Brown laying hens. 1. Performance and egg quality. Rev. Fac. Med. Vet. Zootec. Univ. 5. Paulo, 25(2): 297-307, 1988.

SUMMARY: One hundred twenty eight Hisex hens ( 64 sixty three week-old Hisex
White and 64 sixty four week-old Hisex Brown) were divided into eight groups containing 16 hens each. 4 experimental treatments were prepared by addition of choline to a corn-soy basal diet. The methionine level was $0.253 \%$ for all the experimental diets, equivalent to $80 \%$ of the Natianal Research Council requirements. The experiment was conducted for four 28-day periods (from April 10 to July 31). Egg production, feed conversion (kg/kg eggs) and percentage of shell did not differ significantly hotween etraine Foar rnmareinn (kg/dozen eggs) and Haugh units were significantly higher for Hisex White strain. The shell thickness and egg specific gravity of the brown shell eggs were significantly greater than the white shell eggs. Hen performance and albumen height (Haugh units) did not differ significantly for any level of choline supplementation. Choline was effective in improving the egg shell quality (percentage of shell, thickness shell and egg specific gravity).

UNITERMS: Choline; Eggs, shelb aualitv; Hen performance

REFERENCIAS BIBLIOGRAFICAS

1 - BROOKS, L.G. \& CREGER, C.R. Methionine and choline relationship in the nutrition of the commercial laying hen. Poult. 5ci., 62:1391, 1983.

2 - BUSS, E.G. Genetic differences in avian egg shell formation. Poult. Sci., 61:2048-2055, 1982 .

3 - CRAWFORD, J.S.; GRIFFITH, M.; TEEKELL， R.ं.; WATTS, A.B. Choline requirement as it influences egg production and feed consumption in laying hens. Poult. Sci., 46:1249-1250, 1967.

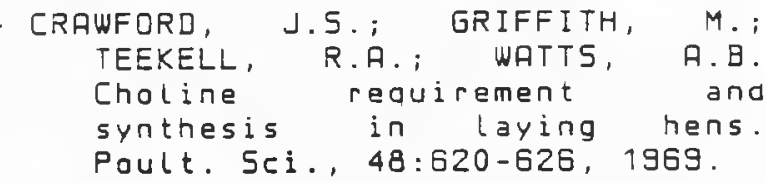

5 - CURTIS, P.A.; GARDNER, F.A.; MELRev. Fac. Med. Vet. Zootec. Univ. S. Paulo. 25(2): 297-307, 1988.
LOR, D.B. A comoarison of selected guality and compositional characteristics of brown and white shell eggs. I. Shell quality. Poult. Sei., $64: 297-301,1985$.

6 - CURTIS, P.A.; GARDNER, F.A.; MELLOR, D.B. $A$ comparison of selected quality and compositional characteristics of brown and white shell eggs. II. Interior quality. Poult. 5ci., 64:302306, 1985 .

7 - DUNCAN, D.B. Multiple range and multiple $F$ tests. Biometrics, $11: 1-42,1955$.

8 - FARNSWORTH JUNIOR, G.M. \& NORDSKOG, A.W. Breeding for egg quality. 3. Genetic differences in sheli caracteristics and other egg quality factors. Poult. 5ci.. $34: 16-26,1955$. 
9 - FERNANDES, E.A.; ᄃAMPOS, E.J.; FERREIRA, M.O.O.; BAIAO, N.C. ClOreto de colina, sulfato de sodio e DL-metionina em dietas de postura. In: CONGRESSO LATINOAMERICANO DE AUICULTURA/CONGRESSO BRASILEIRO DE AUICULTURA, 8., Camboriu, 1983. Anais. p.366377 .

10 - GRIFFITH, M.; OLINDE, A.J.; SCHEXNAILDER, R.; DAVENPORT, R.F.; MCKNIGHT, W.F. Effect of choline, methinnine and vitamin B12 on liver fat, egg production and egg weight in hens. Poult. Sci., 48:2160-2172, 1969.

11 - HAMILTON, R.M.G. Methods and factors that effect the measurement of egg shell quality. Poult. Sci., 61:20222039, 1982 .

12 - HENNIG, A.; LUDKE, ᄃ.; FLACHOWSKY, E. Layers found more independent of supplement than many other animals in choline requirements. Feedstuff $5, \quad 57: 22$, $27-28,30,1985$.

13 - IZAT, A.L.; GRRDNER, F.A.; MELLOR, D.B. Effects of age of bird and season of the year on egg quality. I. Shell quality. Poult. Sci., 64:1900-1906, 1985.

14 - IZAT, A.L.; GRRDNER, F.A.; MELLOR, D.B. The effects of age of bird and season of the year on egg quality. II. Haugh units and compositional attributes. Poult. sci., 65:726-728, 1986.

15 - KESHAVARZ, K. \& AUSTIC, R.E. An investigation concerning the possibility of replacing supplemental methionine with choline in practical laying rations. Poult. Sci., 64:114-118, 1985 .

16 - MARCH, B.E. Choline supolementation of layer diets containing soybean meal or rapeseed meal as protein supplement. Poult. Sei., $60: 818-823,1901$.

17 - Miles, R. . \& HARMS, R.H. A choline-sulfate response in layer diets containing inadequate me- thionine. Poult. Sei.

(supp.1):151, 1984.

18 - MILES, R.D. \& HARMS, R.H. Proper choline supplementation of laying hen feeds. In: FLORIDA NUTRITION CONFERENCE, GainesvilLe, 1985. Proceedings. D.2739 .

19 - MILES, R.D.; RUIZ, N.; HARMS, R.H. Methionine, choline, sulfate: a three-way interre! at: $=r s h i z$ navealed. Part 2. New studies revealing a three-way interrelationship. Feedstuffs. $56: 30-34,1984$.

20 - MIles, R.D.; RUIZ, N.; HARMS, R.H. Response of laying hens to choline when fed practical diets devoid of supplemental sulfur amino acids. Poult. Sci., 65:1760-1764, 1986 .

21 - NATIONAL RESEARCH COUNCIL Nutrient requirements of poultry. 8.ed. Washington, National Academy of Sciences, 1984.

22 - NESHEIM, M.ᄃ.; NORUELL, M.J.; CEBALLOS, E.; LEARCH JUNIOR, R.M. The effect of chaline supplementation of diets far growing pullets and laying hens. Poult. Sci., 50:820-831, 197?.

23 - RUIZ, N.; MILES, R.D.; WILSON, H.R.; HARMS, R.H. Choline supplementation in the diets of aged White Leghorn hens grouped according to body weight. Poult. Sci., 62:1028-1032, 1983.

24 - 5CHEXNAILDER, R. \& GRIFFITH, M. Liver fat and egg production of laying hens as influenced by choline and other nutrients. Poult. Sei., 52:1188-1194, 1973.

25 - SNEDECoR, G.W. \& COCHRAN, W.G. Statistical methods. 6.ed. Ames, Iowa State University Press, 1967.

$2 S$ - TSIAgBE, U.K.; KANG, C.W.; SUNDE, M.L. The effect of choline supplementation in growing pullet and laying hen diets. Poult. Sci., 61:2060-2064, 1982.

Recebido para publicaca em 27/08/87

Aprovado para publicacaro em 04/08/88

Rev. Fac. Med. Vet. Zootec. Univ. S. Paulo, 25(2): 297-307, 1988. 